\title{
ESTETIZAÇÃO DA ESCRITA PROSAICA
}

\section{MAKING MORE AESTHETIC THE PROSAIC WRITING}

\author{
Celina Maria Moreira de MELLO ${ }^{44}$
}

\begin{abstract}
RESUMO: Apresento alguns resultados do Projeto de Pesquisa "Do literário e do prosaico, interrogações sobre o realismo", desenvolvido com apoio do CNPq, de 2009 a 2012, e que tinha como um de seus objetivos categorizar os processos de estetização de cenas genéricas prosaicas na instauração de um novo sistema de escritura, na literatura francesa da Monarquia de Julho (1830-1848), em livros que chamei de "formas literárias experimentais". Destaco o jogo entre tradição e inovação na coletânea ilustrada, $O$ diabo em Paris, publicada por Hetzel em 1845.
\end{abstract}

PALAVRAS-CHAVE: Romantismo; Realismo; Criação literária; Prosa; Gravura.

ABSTRACT: This is a presentation of the results of the research project "From the literary to the prosaic, interrogations about realism", carried out with the support of CNPq, from 2009 to 2012, which aimed at the categorization of aesthetics processes of prosaic genre scenes in the implementation of a new writing system in French literature during the July Monarch (1830-1848), in books I have called "experimental literary forms". I highlight the interplay between tradition and innovation in the compilation The devil in Paris, published by Hetzel in 1845.

KEYWORDS: Romanticism; Realism; Literary creation; Prose; Engraving.

A literatura, em todos os seus suportes, a revista, o teatro, o romance, concorre com o jornal para dar conta deste cotidi-

ano.

THÉRENTY, 2007, p. $26^{45}$

44 Departamento de Letras Neolatinas. Programa de Pós-Graduação em Letras Neolatinas - Faculdade de Letras - Universidade Federal do Rio de Janeiro (UFRJ) - Ilha do Fundão - CEP 21941-590 - Rio de Janeiro RJ - Brasil - E-mail: celina.mello@pq.cnpq.br

45 Traduções da autora, exceto quando explicitamente referido. 


\section{Discussão teórica}

Apresentam-se, neste breve ensaio, alguns resultados do projeto de pesquisa $D o$ literário \& do prosaico; interrogações sobre o realismo, desenvolvido com bolsa de produtividade em pesquisa do CNPq, de 2009 a 2012. O projeto tinha entre seus objetivos gerais consolidar a noção heurística de um espaço-histórico romântico, que encena discursivamente uma episteme moderna, na literatura francesa, e desenvolver o conceito foucaultiano de formações discursivas, nos estudos literários, aproximando-o da noção de longa duração da Ecole des Annales (Cf. BLOCH, 2001; BRAUDEL, 1969; BURKE, 1992). Seus objetivos específicos visavam levantar os traços de uma estética realista na cenografia enunciativa de formas literárias experimentais, na literatura francesa romântica, associadas a uma cena política liberal; para categorizar as cenas genéricas prosaicas na instauração de um novo sistema de estetização da escritura, na literatura francesa da Monarquia de Julho (1830-1848). Visavam, igualmente, relacionar as estratégias de legitimação enunciativa das novas cenas genéricas prosaicas, com as lutas simbólicas, no campo artístico, para conferir prestígio, na pintura, às cenas de gênero e, na gravura, à representação de costumes.

Neste ensaio é dado destaque ao jogo entre tradição e inovação na coletânea ilustrada Le diable à Paris; Paris et les Parisiens. Paris, Hetzel, 1845 (O diabo em Paris; Paris e os parisienses), com ênfase na relação entre o texto e as vinhetas e/ou ilustrações, que constrói um novo espaço de legitimação para gêneros em prosa, em movimento análogo ao dos gêneros da pintura acadêmica, na França.

\section{De diabos e de quadros parisienses}

O livro inscreve-se em uma tradição literária, cujos textos fundadores são o romance picaresco de Lesage (1668-1747) Le diable boiteux (O diabo coxo), publicado em 1707, que se estrutura em torno da curiosidade de Asmodeu, o diabo coxo, o qual levanta os tetos de Madrid (na verdade Paris), para expor o que ali ocorre no segredo das alcovas; e os primeiros Tableaux de Paris (Quadros de Paris), de Sébastien Mercier (1740-1814), publicados entre 1781 e 1800, em que são descritas cenas de costumes do cotidiano parisiense. Estas correspondem, na pintura, a cenas de gênero, as quais, desde o século XVIII, nos Salões de Pintura e Escultura, juntamente com os retratos, já tinham a preferência do público. 
Le diable à Paris (O diabo em Paris) foi publicado por Hetzel e traz como subtítulo Paris et les Parisiens, moeurs et coutumes, caractères et portraits des habitants de Paris, tableau complet de la vie privée, publique, politique, artistique, littéraire, industrielle, etc., etc. (Paris e os Parisienses, hábitos e costumes, caracteres e retratos dos habitantes de Paris, quadro completo de sua vida privada, pública, política, artística, literária, industrial, etc., etc.). É um livro de autoria coletiva, publicado em forma seriada em 1844 e em dois volumes em 1845-1846, que retoma a fórmula de Paris ou Le livre des Cent-et-un (Paris ou o livro dos cento e um), de publicação anterior (1831-1834), apresentando, contudo, um fio condutor que articula todas as narrativas, que é a missão que Satã confia a um de seus demônios, Flammèche. Este deve dar conta toda semana por escrito a seu mestre, o mais exatamente possível, de tudo o que ocorre em Paris (Cf. STAHL, 1845, p. 23).

$\mathrm{O}$ diabo representado na vinheta não é mais Asmodeu, mas Flammèche, um diabo preguiçoso, secretário particular de Satã, que em vez de cumprir pessoalmente a missão, recolhe em uma gaveta, "A gaveta do diabo", todas as contribuições dos vários escritores que o ajudarão na tarefa. Entre os autores que contribuem para o livro, podemos citar, em uma lista não exaustiva, J. P Stah ${ }^{46}$ (1814-1886), Balzac (1799-1850), George Sand (18041876), Alfred de Musset (1810-1857), Gérard de Nerval (1808-1855), Théophile Gautier (1811-1872), Léon Gozlan (1803-1866) e Alphonse Karr (1808-1890).

O livro, que traz a menção à contribuição dos desenhistas em sua folha de rosto, teve imenso sucesso, devido em grande parte a seus dois ilustradores, Bertall, anagrama de Albert d'Arnoux (1820-1882), ilustrador das obras completas de Balzac, e Gavarni, pseudônimo de Sulpice Guillaume Chevalier (1804-1866) (cf. MILNER, 2007, p. 651).

Desde a capa, que anuncia a coleção de que faria parte este livro, vê-se o projeto de conferir à ilustração o mesmo estatuto do texto literário. Assim, a coleção se chama Les chefs-d'oeuvre de la littérature et de l'illustration (As obras-primas da literatura e da ilustração). E o prólogo, escrito pelo editor em sua persona de autor, ressalta o caráter dual desta colaboração: "Bref, chacun mit à sa disposition, ceux-ci leur plume, ceux-là leur crayon." ("Em suma, cada um colocou a sua disposição, alguns a pena, outros o lápis" -

46 J.P. Stahl é o pseudônimo do editor Pierre Jules Hetzel, quando este assume o papel de escritor. 
STAHL, 1845, p. 6), o que, desde o início nesta obra, confere simbolicamente à gravura, o mesmo valor da literatura.

Em uma gravura situada no verso da falsa folha de rosto, ou seja, em vis-à-vis do título na folha de rosto, Gavarni representa Flammèche como um diabo disfarçado de dandy. Ele está usando um fraque e segura uma lanterna mágica na mão esquerda, enquanto examina com uma luneta em sua mão direita, o mapa de Paris. Nas costas carrega a cesta de palha, em que recolhe os textos escritos por seus "colaboradores". Flammèche seria o próprio editor Pierre Jules Hetzel o mesmo J.P. Stahl que assina o Prólogo, enquanto Satã seria uma charge representando o rei Luis Filipe (cf. MILNER, 2007, p. 651).

O prólogo apresenta o projeto editorial, de bandeira ironicamente moderna: "esses pigmeus são gigantes e, comparados a suas mulheres, esses próprios gigantes não passam de pigmeus" (STAHL, 1845, p. 6). A afirmação retoma o conhecido argumento de Charles Perrault (1728-1703), na Querela dos antigos e dos modernos (cf. NASCIMENTO, 2007, p.35-43). Para os defensores dos antigos, gigantes da tradição da antiguidade greco-latina, os modernos são como anões em costas de gigantes. O topos é aqui reformulado: os modernos seriam anões - pigmeus dá o toque pitoresco do exotismo romântico - que, ao imitarem os antigos se tornam maiores que seus modelos. E assume um tom galante, levando em conta a importância do público leitor feminino, para o sucesso de determinados gêneros literários: comparados a suas mulheres os modernos gigantes não passam de pigmeus.

O editor enfatiza a diversidade dos pontos de vista, obtida pelo grande número de autores, o que inova em relação ao padrão retórico neoclássico, o qual exige um plano que assegure a unidade da obra e que respeite o uso da regra da razão. O método, as classificações e a razão compõem as regras de um paradigma do conhecimento legitimado, cuja fundação se atribui a Descartes:

[...] foi decidido que para resolver a dificuldade não seria seguido plano algum. Naquele momento foram feitas as afirmações mais espirituosas e mais sensatas contra os métodos e contra as classificações, que tornam tudo muito pesado sem nada iluminar, em suma contra a regra e contra a própria razão. (STAHL, 1845, p. 6). 
A cidade de Paris é comparada a um espaço teatral, em que os pontos de vista serão tão variados quanto aqueles que se tem dos diferentes lugares de um teatro - "plateia, camarotes e anfiteatro" (STAHL, 1845, p. 6) - quebrando com a visualidade única do espaço cênico e teatral do teatro à italiana, chamado de olho do príncipe, que é centro, origem e fim da unidade: "A verdade será encontrada entre esses diversos julgamentos" (STAHL, 1845, p. 6). Tal diversidade pode provocar "uma bela desordem", que é, para Stahl e seus autores unânimes, representados na assembleia convocada por Flammèche, "um efeito da arte" (STAHL, 1845, p. 6). A beleza moderna é diversa e não se opõe à desordem.

Duas grandes direções temáticas parecem estruturar o livro e se encontram entrelaçadas no romance, cujos capítulos são como curtos esquetes dramáticos: a apresentação de tipos populares e pequenas cenas da vida cotidiana. O pitoresco romântico, efeito de estranhamento no espaço que produz o exótico, e efeito de deslocamento no tempo que se expressa no gosto pelos temas medievais, é suplantado pela vitrine de uma Paris popular, com seus tipos do presente. Estes são socialmente distantes do leitor burguês parisiense, assim como os espaços urbanos em que circulam constituem para aquele um novo exotismo. Paradoxalmente, este gênero será apreciado por leitores do mercado internacional do livro francês, que nele identificam o modelo parisiense.

Há uma grande predominância de tipos femininos: a parisiense, a operária, a costureirinha, mas também são apresentados como figuras de interesse os transeuntes, as pessoas que frequentam os salões da alta sociedade ou o rico herdeiro. Os diferentes espaços são cenários que vão sendo exibidos ao longo do livro, seja nas curtas narrativas, seja nas gravuras que formam sequências: a escola de natação, a Bolsa de valores, os bulevares, a praça Vendôme. Não somente os diversos capítulos podem ser comparados ao que o público vê de diferentes pontos no teatro à italiana, mas a variedade de personagens e situações faz de Paris um grande palco, com uma multiplicidade de cenários, atores e gêneros. A peça que se representa na sociedade - Le monde - só existiria em Paris; é um gênero insignificante, uma "peça invisível" com atores medíocres, que representam uma peça insípida e banal - cuja ação se passa nos bastidores. O narrador servirá de mediador para um leitor que nada ouve, vê ou entende, do espetáculo social a que assiste. As falas são ditas como apartes: 
Ser espirituoso na sociedade é falar para não dizer nada e, esta inteligência sendo especialmente aquela dos que não são espirituosos, vai daí que a sociedade é um teatro em que os figurantes, os comparsas, os terceiros apaixonados, os tenores leves, os novatos e os alunos dos bancos escolares parecem, à primeira vista, representar os papéis mais importantes e ocupar todo o palco - os diretores normalmente se calam ou se limitam a soprar o texto a seus dublês, quando a isso são obrigados [...] Ao mesmo tempo em que se vê esta peça visível, é representada uma peça invisível; esta peça invisível é que confere tanto interesse a essas reuniões insípidas e banais que se chamam reuniões sociais.

A peça invisível está toda nos apartes, nos bastidores e na plateia, mais do que no palco. (STAHL, 1845, p. 134).

Ao comentar o jogo entre a peça visível e aquela dos bastidores que a coletânea desvela, Stahl separa nitidamente as críticas que faz ao homem dos salões, das críticas à mulher da sociedade, que é, em última análise, sua leitora. Acentuando seu caráter teatral, em alguns textos o espaço é indicado no título, como uma didascália que situa o pequeno esquete, reproduzido, graficamente, como uma cena de teatro, tal como "Sous le maronnier des Tuileries - Sous les tilleuls de la place Royale - Dans le jardin du Luxembourg" ("Debaixo da castanheira dos Tuilerias; Sob as tílias da praça Royale; No jardim do Luxemburgo"), de autoria de Octave Feuillet (STAHL, 1845, p. 179-182). Não há nos textos a separação que aparece nas gravuras da coletânea, entre os retratos e os cenários urbanos em que encontramos os tipos retratados, os dois grupos de textos se formam a partir de predominâncias, e os títulos às vezes enganam.

Um tema a entrelaçar a diversidade é o do jovem escritor ou artista, que projeta em Le diable à Paris seu olhar sobre os processos de criação literária e os circuitos de publicação e circulação de escritos, que constituem o cotidiano com que se defrontam os escritores, como em "A quoi on reconnait un homme de lettres à Paris, et ce qu'on y entend par ce mot: un livre" ("Como se reconhece um homem de letras em Paris, e o que nessa cidade se entende por esta palavra: um livro" - STAHL, 1845, p. 43) de Charles Nodier, "Un mot sur les journaux - Moyen facile offert aux journaux pour perdre tous leurs abonnés." ("Uma breve exposição sobre os jornais - Meio fácil para perder todos os assinantes" - STAHL, 1845, p. 53-55) de Léon Gozlan, "Mademoiselle Mimi Pinson Profil de grisette” (“A senhorita Mimi Pinson - Perfil de costureirinha” - STAHL, 1845, p. 116-125) de Alfred de Musset, "Le théâtre à Paris, ce que c'est qu’un théâtre” ("O teatro 
em Paris, o que é um teatro" - STAHL, 1845, p. 252-253) de Léon Gozlan ou “Des ouvriers de l'esprit et de ceux qui ne dînent pas" ("Dos operários da mente e daqueles que não jantam" - STAHL, 1845, p. 263). Assim, para Charles Nodier, acadêmico que goza de grande autoridade entre os autores românticos, contrariamente aos autores da antiguidade, Pitágoras, Demócrito, Sócrates ou Epicuro, as letras agora se confundem com seu modo de publicação em formato de livro:

Paris é, sem dúvida alguma, a cidade do mundo em que há o maior número de homens de letras. Esta abundância de escritores que se nota, em Paris, origina-se provavelmente do fato de que, para ser um homem de letras em Paris, é preciso ter feito um livro [...] Ora, um livro é uma ideia, ou algo que lembre uma ideia, ou até algo que não lembre nada, e cujo nome ocupa habitualmente a parte superior de um in-oitavo de quatrocentas páginas. (NODIER in STAHL, 1845, p. 43).

\section{A escritura do cotidiano}

Entre as duas coletâneas, Paris ou Le livre des Cent-et-un e Le diable à Paris, a gravura assumiu um estatuto comparável ao da literatura, ou pelo menos, comparável a um certo tipo de literatura industrial, como aponta Sainte-Beuve a respeito do romance de folhetim (Cf. SAINTE-BEUVE in DUMASY, 1999). O projeto estético pode ser compreendido em suas relações com a cena de gênero na pintura e o vaudeville, no teatro. Mas à matriz do vaudeville deve ser acrescida a força de novos gêneros das letras produzidos por aquilo que Marie-Ève Thérenty chama de "colusão entre a esfera dos letrados e a dos 'jornalistas'" (2007, p. 13). Thérenty marca a relação de uma nova poética do cotidiano com o esprit Paris, artigo que se opõe ao editorial de jornal e teria sua origem na sociabilidade dos salões parisienses, associando as nouvelles à la main, com as piadas de salão, mas deve-se levar em conta, igualmente, a forte marca do teatro de vaudeville, a encenação de curtas cenas e uma sociabilidade de bulevar, também ligada à cultura oral, popular. Podemos, aqui, pensar em um gênero narrativo que resulte de uma triangulação entre a crônica cotidiana dos jornais parisienses, o fait divers e o romance policial.

Uma questão deve ser colocada: esta poética do cotidiano vem do jornalismo à literatura ou podemos afirmar o movimento inverso? Se jornais e revistas inauguram "novas práticas de publicação" (THÉRENTY, 2007, p. 16) que desestabilizam as poéticas por não integrarem o cânone, afirmamos que aquelas não podem ser entendidas apenas pelo 
viés do jornalismo, pois seus autores provêm do campo dos letrados. A literatura apropriase de modos de escrita do jornal, mas já que não há ainda, naquele momento, jornalistas no sentido atual do termo, senão homens de letras e políticos que escrevem nos jornais, o que vemos é serem primeiro transportados para os jornais gêneros que o cânone considera menores, que se originariam de jogos de salão, vaudevilles e nouvelles à la main ou petites nouvelles (curta notícia ou contos), que por sua vez retornam ao campo literário, ao almejar o suporte "livro", e, no recurso a vinhetas, gravuras destacáveis e prefácios, buscam ocupar um lugar legitimado. A petite nouvelle se definirá, então, como "a escrita de uma narrativa mínima com uma tentativa de apagamento da instância observante." (THÉRENTY, 2007, p. 24).

Algumas características do esprit Paris (Cf. THÉRENTY, 2007, p. 157) podem ser encontradas nas narrativas de tais coletâneas: a exposição do não acontecimento, o pequeno, o banal; a mise en scène que faz do privado um espetáculo, para vizinhos ou transeuntes, no plano narrativo, representantes do leitor na cena enunciativa (Cf. MAINGUENEAU, 2003, 2004) e a estereofonia de falares de grupos específicos, sobretudo populares.

O olhar voltado para personagens da cena parisiense e aquilo que escondem os pequenos fatos do cotidiano constroem uma dupla enunciação: a do observadorpersonagem que não interpreta e sofre a atualidade, e a da instância autoral que se manifesta pela ironia com que interpreta o olhar do outro. O tom será, de modo geral, o da conversa ou da carta, opondo-se ao tom da tribuna ou do púlpito; ou ainda será o leve tom dos diálogos que se ouvem nos bulevares, espaço público aberto que se opõe ao espaço público fechado dos circuitos de poder. Para Thérenty (2007), as múltiplas vozes no jornal criam um efeito de cacofonia; afirmamos que nessas coletâneas, a autoria múltipla cria um efeito de grupo, que fortalece a renovação da proposta estética.

Assim, não estamos diante de um mero registro, sem interpretações, que será reivindicada mais tarde pela estética realista. Há um falso apagamento do observador, e a observação se dá em dois planos: o do espanto, com o olhar do outro, o outro leitor de outra classe social, e o plano da ironia, expressa nos cortes narrativos ou, conforme o autor, em posicionamentos explícitos. 
O jogo é de contrapontos. No cotexto do jornal, o esprit Paris é uma segunda voz que faz o contraponto do discurso político das manchetes e dos editoriais. No cotexto das coletâneas narrativas do prosaico, há ainda narrativas próximas dos temas e personagens do melodrama - o que aparece, por exemplo, no famoso e já citado conto Mademoiselle Mimi Pinson - profil de Grisette, de Alfred de Musset - ou do vaudeville, fácil adaptação das comédias. São encenações de uma fala e de um cotidiano privados que expõem o detalhe aparentemente inexpressivo, mas carregado de força dramática, ou seja, a face oculta do folhetim, como o outro lado da lua, e a face real do que escapa ao olhar do leitor, mas que o cerca em seu cotidiano...

A ficcionalização do trivial cotidiano não se confunde com a ficcionalização do excepcional, alimento do folhetim. A temporalidade é feita do presente, sem a sombra da História que faz do passado construído um caminho para utopias, e que os romances históricos do romantismo apresentam como um horizonte futuro e às vezes como um destino. Há uma suspensão da linearidade histórica e ênfase no tempo presente, que abre um espaço de representação a cenas com leituras múltiplas e inúmeras interpretações. A poética do cotidiano, assim, pode ser compreendida como trazendo o cotidiano como tema, cujo comentário é dado pela ironia no tom. O caminho de pensar nesta poética leva-nos a indagar se não haveria um cotidiano lírico, um cotidiano trágico ou épico? Neste caso preciso, malgrado a força dramática de certas narrativas, haveria um esvaziamento do pathos.

\section{Resultados preliminares}

Apreender o traço realista no espaço-histórico da literatura francesa, recortado neste projeto, permitiu isolar este traço, ao relacioná-lo com um conjunto de regularidades apresentadas como transhistóricas, em seu processo de autolegitimação, posicionamento de que é emblemático o texto de Champfleury, Du réalisme; lettre à Madame Sand, publicado pela revista L'Artiste em setembro de 1855 (reeditado por Michel Lévy, 1857). Uma estética do prosaico, rejeitada como vulgar e, a seguir, acusada pelos defensores da chamada arte pela arte de compor uma estética do feio (Cf. GAUTIER, 2000) provoca a busca pelo preenchimento da função discursiva de fiador, em uma tradição que remontaria aos novos gêneros literários de sucesso junto ao público, no século XVIII. 
A genealogia dessa estética pode ser lida nos prefácios e nas vinhetas de capa, que formam uma construção de seu passado, a tradição literária que proclamam, o que justificaria, aos olhos do leitor, a leveza, para não dizer a leviandade, a futilidade, a contemporaneidade, ou seja, a modernidade dos temas.

O jogo entre o passado e o presente pode ser acompanhado, no passo a passo da leitura das coletâneas de narrativas em prosa, de autoria compartilhada, voltadas para tipos populares da cena parisiense a que chamamos de início formas literárias experimentais, e que pertencem ao gênero de petite nouvelle.

É evocada uma necessidade histórica, de que têm consciência editores e autores, e que é tributária, por um lado, de um diagnóstico generalizado de viverem em uma nova sociedade, resultando da enorme ruptura social que representou a Revolução Francesa, produzindo tipos e uma cena social que necessitam ser explicados, e, por outro lado, de que o modelo de explicação de que dispõem é a causalidade histórica.

Ora, como afirma Paul Veyne: "Em cada época, os contemporâneos se encontram deste modo inseridos nos discursos como em bocais falsamente transparentes, ignoram quais sejam estes bocais e até mesmo que haja um bocal." (2008, p. 26). Assim, a opacidade em que se encontram os contemporâneos de cada época, no que se refere ao discurso que os encerra, explicaria a busca dos produtores culturais pela tradição popular que constitui o exato contraponto de sua formação escolar, na tradição das humanidades, e que pode ser um trunfo, na luta por um lugar legitimado no campo literário, com seus correlatos: publicar, vender tiragens cada vez maiores e alcançar um público leitor que não tem a mesma formação.

\section{REFERÊNCIAS}

BLOCH, M. Apologia da História ou o ofício do historiador. Trad. André Telles. Rio de Janeiro: J. Zahar, 2001.

BRAUDEL, F. Histoire et sciences sociales; la durée. In: . Ecrits sur l'histoire. Paris, Flammarion, 1969. p. 41-83.

BURKE, P. (Org.). A escrita da História: novas perspectivas. Trad. Magda Lopes. São Paulo: UNESP, 1992.

CHAMPFLEURY. Le réalisme. Paris: Michel Lévy frères, 1857. 
CHARTIER, R. ; MARTIN, H.-J. Histoire de l'édition française; le temps des éditeurs. Paris: Fayard, 1990.

GAUTIER, Th. Courbet; le Watteau du laid. Biarritz: Atlantica, 2000.

JANIN, J. Asmodée. In: JANIN, J. et al. Paris ou le livre des Cent-et-un. T.1 Publié chez Ladvocat, libraire de S.A.R. le duc d'Orléans, 1831. p.1-15. [Documento eletrônico, disponível em www.gallica.bnf.fr - consultado em 16/02/2010]

LE SAGE. Le diable boiteux augmenté des béquilles du diable boiteux. Paris, Dabo, Tremblay, Feret et Goyot, 1819. [Documento eletrônico, disponível em www.google.books - consultado em 22/02/2010]

MAINGUENAU, D. Linguistique pour le texte littéraire.4 ed. (Entièrement révisée et augmentée) Paris: Nathan, 2003.

. Le discours littéraire; paratopie et scène d'énonciation. Paris: Armand Colin, 2004a. (Discurso literário. Trad. Adail Sobral. São Paulo, Contexto, 2006).

MELOT, M. Le texte et l'image. In: CHARTIER, R.; MARTIN, H.-J. Histoire de l'édition française; le temps des éditeurs. Paris: Fayard, 1990. p. 329-348.

MERCIER, S. Tableaux de Paris. Paris, Virchaux \& Compagnie, 1782. [documento eletrônico, disponível em http:/www.archive.org./details/tableaudeparis01mergoog consultado em 23/08/2012]

MILNER, M. Le diable dans la littérature française; de Cazotte à Baudelaire 17721861. Paris: José Corti, 2007.

NASCIMENTO, R. Andrade do. Gênero clássico, processo moderno: o uso do paralelo por Charles Perrault. Terra roxa e outras terras - Revista de Estudos Literários, Londrina, v.9 (2007), p. 35-43. [revista eletrônica, disponível em http://www.uel.br/cch/pos/letras/terraroxa - consultada em 27.06.2012]

SAINTE-BEUVE. De la littérature industrielle. In: DUMASY, L. La querelle du romanfeuilleton. Grenoble, ELLUG, 1999. p. 25-43 (Revue des Deux Mondes, $1^{\text {er }}$ septembre 1839).

STAHL, J. P. et al. Le diable à Paris; Paris et les Parisiens. Paris, Hetzel, 1845. [Documento eletrônico, disponível em www.gallica.bnf.fr - consultado em 12/04/2010]

STAHL, P.-J. Prologue, comment il se fit qu'un diable vint à Paris et comment ce livre s'ensuivit. In: . Le diable à Paris; Paris et les Parisiens. Paris, Hetzel, 1845. p. 1-30 [Documento eletrônico, disponivel em www.gallica.bnf.fr - consultado em 12/04/2010]

THÉRENTY, M-È. La littérature au quotidien; poétiques journalistiques au XIXe siècle. Paris: Seuil, 2007.

VEYNE, P. Foucault, sa pensée, sa personne. Paris: Albin Michel, 2008.

Artigo recebido em 28/08/2012

Aceito para publicação em 24/09/2012 